\title{
ISOLASI DAN IDENTIFIKASI KOMPONEN KIMIA EKSTRAK N-HEKSAN DAUN PALA (Myristica fragrans)
}

\author{
Virsa Handayani \\ Fakultas Farmasi Universitas Muslim Indonesia Makassar \\ Email : virsaichafarmasi@yahoo.com
}

\begin{abstract}
Nutmeg plant is a multi-purpose plant because each part can be utilized in the industry. Nutmeg leaves contain essential oils and phenolic compounds. Essential oils are used as traditional medicine ingredients and as raw material for the manufacture of cosmetics, soaps, perfumes and others. This study aimed to isolate and identify the chemical components in the leaves of nutmeg (Myristica fragrans). Have done isolation and Identification of chemical components of the methanol extract of leaves pala (Myristica fragrans.) of 500 grams to determine the class of chemical components caontained in the leaf pala (Myristica fragrans.). The methanol extract which obtained by maseartion method 9,45 grams continued by solid liquid partition with $n$-hexane 4,61 grams extract. $N$-hexan extract isolated by column chromatography method obtained 37 bottles vials. Fraction $D$ of the merger based on the appearance of spotting the chromatograms isolated by preparative thin-layer chromatography method, obtained 3 band. D.1 fractions isolated by TLC obtained a stain. In fractions spotting $D .1$ is obtained by testing a single two-dimentional TLC ang the elution system of multi eluen. Interpretation UV-Visible spectra data showed maximum absorption at a wavelength of $273 \mathrm{~nm}$ and showed infrared fungtional group $(\mathrm{OH})$ on the wave number $\left(3927.78 \mathrm{~cm}^{-1}, 3828.59 \mathrm{~cm}^{-1}, 3743.30 \mathrm{~cm}^{-1}, 3387.93\right.$ $\left.\mathrm{cm}^{-1}\right)$, group $(\mathrm{CH})$ on the wave number $\left(2925.93 \mathrm{~cm}^{-1}, 2859.02 \mathrm{~cm}^{-1}, 2364.17 \mathrm{~cm}^{-1}\right)$, alken group $(C=C)$ aromatik on the wave number $\left(1642.54 \mathrm{~cm}^{-1}, 1565.88 \mathrm{~cm}^{-1}\right.$, $\left.1516.65 \mathrm{~cm}^{-1}, 1458.92 \mathrm{~cm}^{-1}, 1114.33 \mathrm{~cm}^{-1}\right)$, benzene group on the wave number ( $\left.698.24 \mathrm{~cm}^{-1}\right)$. Single spots obtained gave a positive reaction to spotting visualizer class of flavonoids.
\end{abstract}

Key words : Nutmeg, Isolation, Essential Oils.

\section{PENDAHULUAN}

Secara tradisional banyak tumbuhan yang telah dimanfaatkan untuk keperluan obat tradisional dan bahan kosmetik Salah satunya adalah tumbuhan pala (Myristica fragrans) (Chairul, 2000). Tanaman pala merupakan tanaman multi guna karena setiap bagian dapat dimanfaatkan dalam industri. Daun tanaman pala mengandung minyak atsiri dan senyawa fenolik yang dapat disuling untuk memperoleh minyak atsiri. Minyak atsiri tersebut digunakan sebagai bahan pengobatan tradisional dan dapat dieksport untuk tujuan sebagai bahan baku pembuatan kosmetik, sabun, parfum dan lain-lain 
(arrijani, 2005). Kulit dan daun pala sering digunakan sebagai aromatik terutama untuk pengobatan penyakit usus. (hayne,1987).

Pemanfaatan bahan alam sebagai obat tradisional di Indonesia meningkat. Beberapa bahan alam telah diproduksi secara pabrikasi dalam skala besar. Penggunaan obat bahan alam dinilai memiliki efek samping yang lebih kecil dibandingkan obat yang berasal dari bahan kimia, di samping itu harganya lebih terjangkau.

Berdasarkan latar belakang yang menyebutkan bahwa tanaman pala merupakan tanaman multiguna serta banyak digunakan secara empirik oleh masyarakat Indonesia, maka dilakukan isolasi dan Identifikasi senyawa kimia yang terkandung pada daun pala (Myristica fragrans) sehingga dapat menjadikan daun pala (Myristica fragrans) sebagai obat tradisional.

\section{METODE PENELITIAN}

\section{Alat dan Bahan}

Alat yang digunakan adalah Botol penyemprot penampak bercak, chamber (Chamag), eksikator, gelas erlenmeyer (pyrex), inkubator (Memert), seperangkat lampu UV, oven (Memert), seperangkat alat rotavapor (ika werkw @Rvor), seperangkat alat maserasi, spektroskopi IR (FTIR-5400S), spektroskopi UV-Vis

(UV1601Shimadzu), seperangkat alat KLT, seperangkat alat kromatografi lapis tipis, timbangan analitik (Chyo) dan vial.

Bahan yang dipakai adalah Sampel yang digunakan yaitu Air suling, asam sulfat $10 \%$, daun pala (Myristica fragrans), etil asetat, $\mathrm{AlCl}_{3}$, Fanilin- HCL, lod, kloroform, lempeng KLT (E.Merck), lempeng KLT preparatif (E.Merck), metanol, n-heksa, silika Gel G60 F254

\section{Pembuatan ekstrak}

\section{Ekstraksi dengan pelarut metanol secara maserasi}

Simplisia daun pala (Myristica fragrans) sebanyak 500 gram direndam dengan metanol sebanyak 7 liter hingga terendam seluruh simplisia, dan dibiarkan selama 3 hari dengan pengadukan sesekali. Kemudian disaring dan ampasnya diekstraksi kembali dengan cairan penyari sampai terekstraksi secara sempurna. Hasil penyarian yang diperoleh disatukan lalu dipekatkan dengan menggunakan rotavapor. Sehinggga diperoleh ekstrak metanol sebanyak 9,54 gr lalu ditimbang sebanyak 6 gr untuk selanjutnya dipartisi dengan metode padat-cair. 


\section{Ekstraksi padat-cair dengan pelarut n-Heksana}

Ekstrak metanol kental yang ditimbang sebanyak 6 gram disuspensikan dengan $40 \mathrm{ml}$ n-heksan dan dimasukkan kedalam labu erlenmeyer $250 \mathrm{ml}$. batang pengaduk magnetik di masukan kedalam labu Erlenmeyer kemudian diletakan di atas plat. Star disambungkan dengan aruslistrik dan di stel dengan kecepatan yg sesuai. biarkan sampai pelarut jenuh, kemudian suspensi di keluarkan dan di pisahkan antara padatan dengan cairan. Bagian yang tidak larut di masukan kembali kedalam Erlenmeyer dan di tambahkan $40 \mathrm{ml} \mathrm{n-Heksan} \mathrm{yang} \mathrm{baru,}$ lalu lakukan seperti perlakukan pertama. Hasil ekstraksi n-heksana yang diperoleh kemudian diuapkan hingga diperoleh ekstrak n-heksana kering 4,61 gr.

\section{Identifikasi dengan Kromatografi} Lapis Tipis

Ekstrak n-heksana daun pala (Myristica fragrans) ditotolkan pada lempeng silika gel berukuran $8 \times 1 \mathrm{~cm}$ kemudian di elusi dengan eluen $n$ Heksan : etil asetat $8: 2$ setelah terelusi lempeng diangkat dan dikeringkan setelah itu di amati dilampu UV 254 nm dan UV 366 dengan penyemprotan $\mathrm{H}_{2} \mathrm{SO}_{4} 10 \%$.
Isolasi dengan Kromatografi Kolom Penyiapan Kolom

Kolom dibersihkan dan dibilas dengan metanol kemudian dipasang tegak lurus pada statif. Bagian bawah kolom dilapisi dengan kapas. Cairan pengelusi $n$-Heksan : etil asetat (8:2) dimasukkan ke dalam kolom sampai 2/3 bagian kolom kemudian dimasukkan silika gel G.60 sedikit demi sedikit dengan menggunakan corong sampai 2/3 bagian dari kolom. Kolom diketuk-ketuk pada semua sisi secara perlahan-lahan hingga diperoleh lapisan yang mampat.

\section{Isolasi Sampel}

Ekstrak n-Heksan daun pala (Myristica fragrans) sebanyak 2 gram dilarutkan dengan cairan pengelusi $n$ Heksan:etil asetat yang sesuai dengan menggunakan corong. Kertas saring diletakkan di atas permukaan sampel untuk menghindari adanya percikan cairan pengelusi pada saat memasukkan cairan pengelusi. Selanjutnya dimasukkan cairan pengelusi n-Heksan:etil asetat sebanyak $300 \mathrm{ml}$ sedikit demi sedikit ke dalam kolom. Kran kolom dibuka dan ditampung eluen yang keluar ke dalam vial. dan diperoleh 37 vial. Filtrat kemudian ditotolkan ke lempeng KLT dengan ukuran 20x8 cm dan yang memberikan profil kromatogram yang 
sama disatukan dalam satu fraksi, dimana didapatkan 14 fraksi yaitu fraksi $A, B, C, D, E, F, G, H, I, J, K, L$, $M$, dan N. Selajutnya Ketujuh fraksi tersebut diprofil kembali dan fraksi $D$ yang menunjukkan kromatogram pemisahan noda yang baik.

Isolasi dengan metode kromatografi preparative

Ekstrak n-hekan Daun pala (Myristica fragrans) ditotolkan pada lempeng KLTP dengan ukuran $20 \times 20$ $\mathrm{cm}$, selanjutnya dielusi dalam chamber yang berisi eluen $\mathrm{n}$-Heksan:etil asetat (8:2). Jika elusinya sudah mencapai batas, lempeng tersebut dikeluarkan dan dikeringkan di udara kemudian diamati dibawah sinar UV $254 \mathrm{~nm}$ dan $366 \mathrm{~nm}$. Lempeng yang telah diamati diberi batas noda dan dikeruk, Pita-pita yang dihasilkan kemudian ditampung ke dalam tabung sentrifuge selama 10 menit. Hasil kerukan tersebut selanjutnya ditambahkan pelarut methanol absolut dan disaring. Filtrat diuapkan lalu ditambahkan kembali dengan pelarut metanol absolut kemudian filtrat ditotolkan pada lempeng KLT, selanjutnya dielusi dengan eluen $\mathrm{n}$-heksan : etil asetat (8: 2). Jika proses elusi selesai kemudian diamati di bawah sinar UV $254 \mathrm{~nm}$ dan $366 \mathrm{~nm}$. lalu dilanjutkan dengan uji pemurnian.

\section{Uji kemurnian isolat}

\section{Kromatografi lapis tipis dua dimensi}

Kristal yang diperoleh dilarutkan dengan pelarut yang sesuai, kemudian ditotolkan pada lempeng KLT dengan ukuran $10 \times 10 \mathrm{~cm}$. Lalu dielusi dengan eluen $\mathrm{n}$-heksan : etil asetat (8:2) arah pertama dan untuk ke arah kedua. Proses elusi yang kedua dilakukan dengan cara memutar lempeng berlawanan dengan arah jarum jam sehingga hasil elusi yang pertama menjadi titik awal pengelusian untuk yang kedua kali proses elusi yang dilakukan terdapat satu bercak tunggal, maka dapat dikatakan bahwa kristal tersebut adalah komponen kimia yang tunggal.

\section{Elusi sistem multi eluen}

Uji kemurnian isolat juga dilakukan dengan menggunakan beberapa variasi eluen yaitu $n$-Heksan : Etil asetat (8:2), kloroform : metanol (15:6), dan klorofrom : n-heksan (1:1). Penampakan bercak tunggal menandakan bahwa golongan senyawa dari isolat yang diperoleh merupakan komponen kimia yang tunggal. Selanjutnya lempeng tersebut disemprot dengan pereaksi semprot spesifik flavonoid.

\section{Identifikasi dan Karakterisasi}

Identifikasi secara kimia 
Isolat yang tunggal dilanjutkan dengan identifikasi secara kimia yaitu dengan penyemprotan beberapa pereaksi khusus komponen kimia flavonoid yaitu Aluminium Klorida, Vanillin- $\mathrm{HCl}$, dan uap iod. Penggunaan ketiga pereaksi tersebut mengacu pada kandungan flavonoidnya yang mengacu pada buku Cara Mengidentifikasi Flavonoid.

\section{Identifikasi spekroskopi UV-Visible}

Isolat yang diperoleh diidentifikasi dengan spektroskopi UVVisible. Senyawa dilarutkan dalam metanol p.a kemudian cuplikan ditempatkan antara monokromator dan detektor. Spektrum yang dihasilkan direkam pada alat pencatat.

Identifikasi spektroskopi inframerah (IR)

Isolat yang diperoleh dari fraksi dilanjutkan dengan identifikasi spektroskopi inframerah dengan cara menempatkan cuplikan sebagai film yang tipis diantara dua lapisan natrium klorida yang transparan, kemudian ditempatkan pada celah sinar inframerah. Hasilnya direkam pada alat pencatat.

Tabel 1. Hasil ekstraksi daun pala (Miristica fragrans.)

\begin{tabular}{clc} 
No & Ekstrak & Bobot (gram) \\
1. & Metanol & 9,5 \\
2. & Metanol yang dipartisi & 6,14 \\
3. & n-heksana & 4,6 \\
\hline
\end{tabular}

Tabel 2. Nilai Rf dan Warna Bercak pada Profil Kromatogram Ekstrak Metanol Daun Pala (Myristica fragrans)

\begin{tabular}{ccccccc}
\hline \multirow{2}{*}{ Bercak } & \multicolumn{2}{c}{ UV 254 nm } & \multicolumn{2}{c}{ UV 366 nm } & \multicolumn{2}{c}{ Uap lod } \\
\cline { 2 - 6 } & Nilai Rf & Warna bercak & Nilai Rf & Warna Bercak & Nilai Rf & Warna Bercak \\
\hline 1 & - & - & 0,73 & Biru & 0,95 & coklat \\
2 & 0,70 & Hijau & 0,6 & Merah muda & 0,70 & coklat \\
3 & 0,46 & Hijau & 0,46 & Merah muda & 0,46 & coklat \\
4 & 0,30 & Hijau & 0,30 & Merah muda & 0,30 & coklat \\
5 & 0,15 & Hijau & 0,15 & Merah muda & 0,15 & coklat \\
\hline
\end{tabular}


Tabel 3. Nilai Rf dan Warna Bercak pada Profil Kromatogram Ekstrak n-Heksana Daun Pala (Myristica Fragrans.)

\begin{tabular}{ccccccc}
\hline \multirow{2}{*}{ Bercak } & \multicolumn{2}{c}{ UV 254 nm } & \multicolumn{2}{c}{ UV $\mathbf{3 6 6} \mathbf{n m}$} & \multicolumn{2}{c}{ H2SO4 } \\
\cline { 2 - 6 } & Nilai Rf & Warna bercak & Nilai Rf & Warna Bercak & Nilai Rf & Warna Bercak \\
\hline 1 & - & - & 0,73 & Biru & 0,73 & hijau \\
2 & 0,6 & Hijau & 0,6 & Merah muda & 0,6 & hijau \\
3 & 0,44 & Hijau & 0,44 & Merah muda & 0,44 & hijau \\
4 & 0,29 & Hijau & 0,29 & Merah muda & 0,29 & hijau \\
5 & 0,15 & Hijau & 0,15 & Merah muda & 0,15 & hijau \\
\hline
\end{tabular}

Tabel 4. Nilai Rf dan Warna Bercak pada Profil Kromatografi Vial 1-37 Hasil Kolom dari Ekstrak n-heksan daun pala (Myristica fragrans.)

\begin{tabular}{|c|c|c|c|c|c|}
\hline \multirow{2}{*}{ Vial } & \multirow{2}{*}{ Bercak } & \multicolumn{2}{|c|}{ UV 254 nm } & \multicolumn{2}{|c|}{ UV $366 \mathrm{~nm}$} \\
\hline & & Nilai Rf & Warna bercak & Nilai Rf & Warna Bercak \\
\hline 3 & 1 & 0,93 & Merah muda & 0,93 & Merah muda \\
\hline \multirow{5}{*}{$4-5$} & 1 & 0,93 & Merah muda & 0,93 & Merah muda \\
\hline & 2 & 0,90 & Merah muda & 0,90 & Merah muda \\
\hline & 3 & 0,83 & Merah muda & 0,84 & Merah muda \\
\hline & 4 & 0,75 & Merah muda & 0,78 & Merah muda \\
\hline & 5 & - & - & 0,70 & Merah muda \\
\hline 6 & 1 & 0,69 & Hijau muda & 0,69 & Merah muda \\
\hline \multirow{2}{*}{$7-9$} & 1 & 0,67 & Merah muda & 0,63 & Biru \\
\hline & 2 & 0,6 & Merah muda & 0,50 & Merah muda \\
\hline \multirow{3}{*}{10} & 1 & - & - & 0,63 & Biru \\
\hline & 2 & - & - & 0,52 & Merah muda \\
\hline & 3 & - & - & 0,46 & Merah muda \\
\hline \multirow{2}{*}{11} & 1 & 0,36 & hijau & 0.63 & Biru \\
\hline & 2 & - & - & 0,46 & Hijau \\
\hline \multirow{4}{*}{$12-13$} & 1 & 0,47 & Hijau & 0.63 & Biru \\
\hline & 2 & 0,44 & Hijau & 0,47 & MerahMuda \\
\hline & 3 & 0,4 & Hijau & 0,44 & Hijau \\
\hline & 4 & 0,36 & Merah muda & 0,38 & Merah muda \\
\hline \multirow{4}{*}{$14-15$} & 1 & 0,50 & Hijau & 0,50 & Merah muda \\
\hline & 2 & 0,46 & Hijau & 0,46 & Hijau \\
\hline & 3 & 0,4 & Hijau & 0,4 & hijau \\
\hline & 4 & 0,36 & Merah muda & 0,29 & Merah muda \\
\hline \multirow{3}{*}{$16-17$} & 1 & 0,4 & hijau & 0,50 & Hijau \\
\hline & 2 & 0,36 & Merah muda & 0,4 & Merah muda \\
\hline & 3 & - & - & 0,29 & Merah muda \\
\hline $18-29$ & 1 & 0,29 & hijau & 0,41 & Merah muda \\
\hline \multirow{3}{*}{$30-34$} & 1 & 0,36 & Merah muda & 0,32 & Merah muda \\
\hline & 2 & 0,32 & Merah muda & 0,16 & Merah muda \\
\hline & 3 & 0,21 & Merah muda & - & - \\
\hline \multirow{2}{*}{$37-37$} & 1 & 0,30 & Merah muda & 0,30 & Merah muda \\
\hline & 2 & 0,21 & hijau & 0,16 & hijau \\
\hline
\end{tabular}


Tabel 5. Nilai Rf dan Warna Bercak pada Profil Kromatografi Fraksi A - N Daun Pala (Myristica fragrans.)

\begin{tabular}{|c|c|c|c|c|c|}
\hline \multirow{2}{*}{ Fraksi } & \multirow{2}{*}{ Bercak } & \multicolumn{2}{|c|}{ UV 254 nm } & \multicolumn{2}{|c|}{ UV 366 nm } \\
\hline & & Nilai Rf & Warna bercak & Nilai Rf & Warna Bercak \\
\hline$A$ & - & - & - & - & - \\
\hline B & 1 & 0,81 & Ungu muda & 0,81 & Merah muda \\
\hline \multirow{2}{*}{ C } & 1 & 0,81 & Ungu muda & 0,81 & Merah muda \\
\hline & 2 & 0,72 & Ungu muda & 0,72 & Biru \\
\hline \multirow{3}{*}{ D } & 1 & 0,81 & Ungu muda & 0,81 & Merah muda \\
\hline & 2 & 0,72 & Ungu muda & 0,72 & Biru \\
\hline & 3 & 0,56 & Hijau muda & 0,56 & Merah muda \\
\hline \multirow{3}{*}{$E$} & 1 & 0,81 & Ungu muda & 0,72 & Biru \\
\hline & 2 & 0,72 & Ungu muda & 0,50 & Merah muda \\
\hline & 3 & 0,50 & Hijau tua & - & - \\
\hline \multirow{3}{*}{$F-G$} & 1 & 0,50 & Hijau tua & 0,72 & Biru \\
\hline & 2 & 0,40 & Ungu muda & 0,50 & Merah muda \\
\hline & 3 & - & - & 0,40 & Merah muda \\
\hline \multirow{4}{*}{$\mathrm{H}$} & 1 & 0,52 & Hijau tua & 0,72 & Biru \\
\hline & 2 & 0,47 & Hijau tua & 0,6 & Merah muda \\
\hline & 3 & 0,38 & Hijau tua & 0,49 & Hijau tua \\
\hline & 4 & - & - & 0,38 & Hijau tua \\
\hline \multirow{4}{*}{ I-J } & 1 & 0,50 & Hijau muda & 0,72 & Biru \\
\hline & 2 & 0,41 & Hijau tua & 0,55 & Merah muda \\
\hline & 3 & - & - & 0,50 & Hijau tua \\
\hline & 4 & - & - & 0,31 & Hijau tua \\
\hline \multirow{4}{*}{$\mathrm{K}$} & 1 & 0,41 & Hijau tua & 0,72 & Biru \\
\hline & 2 & 0,32 & Ungu & 0,41 & Merah muda \\
\hline & 3 & 0,27 & Ungu & 0,32 & Hijau tua \\
\hline & 4 & - & - & 0,27 & Merah muda \\
\hline \multirow{2}{*}{$L$} & 1 & 0,41 & Hijau muda & 0,41 & Merah muda \\
\hline & 2 & 0,27 & Ungu muda & 0,27 & Merah muda \\
\hline \multirow{2}{*}{ M } & 1 & 0,30 & Hijau muda & 0,30 & Ungu muda \\
\hline & 2 & 0,24 & Hijau muda & 0,24 & Merah muda \\
\hline \multirow{4}{*}{$\mathrm{N}$} & 1 & 0,29 & Hijau muda & 0,29 & Merah muda \\
\hline & 2 & 0,24 & Hijau muda & 0,24 & Merah muda \\
\hline & 3 & 0.18 & Ungu muda & 0.18 & Ungu muda \\
\hline & 4 & 0,09 & Ungu muda & 0,09 & Merah muda \\
\hline
\end{tabular}

Tabel 6. Nilai Rf dan Warna Bercak Kromatogram Lapis Tipis Preparatif Daun Pala (Myristica fragrans.)

\begin{tabular}{ccccccc}
\hline \multirow{2}{*}{ Pita } & \multicolumn{2}{c}{ UV $254 \mathbf{n m}$} & \multicolumn{2}{c}{ UV $366 \mathbf{n m}$} & \multicolumn{2}{c}{$\mathbf{A I C l}_{\mathbf{3}} \mathbf{1 \%}$} \\
\cline { 2 - 7 } & Nilai Rf & Visual & Nilai Rf & Visual & Nilai Rf & Visual \\
\hline I & 0,61 & hijau & 0,61 & Biru & 0,61 & Biru \\
II & - & - & - & & - & - \\
III & - & - & - & & - & - \\
\hline
\end{tabular}


Tabel 7. Nilai Rf dan Warna Bercak Kromatografi Lapis Tipis Dua Dimensi Fraksi D. 1

\begin{tabular}{ccccc}
\hline \multirow{2}{*}{ Sampel } & \multicolumn{2}{c}{ UV 254 $\mathbf{n m}$} & \multicolumn{2}{c}{ UV $\mathbf{3 6 6} \mathbf{n m}$} \\
\cline { 2 - 5 } & Nilai Rf & Visual & Nilai Rf & Visual \\
\hline Arah I & - & - & 0,61 & Biru \\
Arah II & - & - & 0,77 & Biru \\
\hline
\end{tabular}

Tabel 8. Nilai Rf dan Warna Bercak Kromatogram Lapis Tipis Fraksi D.1 dengan Variasi Eluen (Sistem Multi Eluen)

\begin{tabular}{ccccc}
\hline \multirow{2}{*}{ Pelat } & \multicolumn{2}{c}{ UV 254 $\mathbf{n m}$} & \multicolumn{2}{c}{ UV $\mathbf{3 6 6} \mathbf{~ n m}$} \\
\cline { 2 - 5 } & Nilai Rf & Warna Bercak & Nilai Rf & Warna Bercak \\
\hline I & - & - & 0,89 & Biru \\
II & - & - & 0,15 & Biru \\
III & - & - & 0,6 & Biru \\
\hline
\end{tabular}

Tabel 9. Nilai Rf dan Warna bercak Pada identifikasi penampak bercak fraksi D.1 ekstrak $n$-heksan daun pala (Myristica fragrans.)

\begin{tabular}{ccccc}
\hline Plat & Identifikasi reagen & Jumlah bercak & Rf & Warna Bercak \\
\hline 1 & $\mathrm{AlCl}_{3}$ & 1 & 0,48 & Kuning \\
2 & Vanilin $\mathrm{HCL}$ & - & - & - \\
3 & Uap lod & 1 & 0,57 & Berpendar \\
\hline
\end{tabular}

\section{PEMBAHASAN}

Simplisia daun pala (Myristica fragrans.) kering sebanyak 500 gram diekstraksi secara maserasi menggunakan pelarut metanol, menghasilkan ekstrak metanol kental sebanyak 9,5 gram. Ekstrak metanol kental selanjutnya dipartisi padat-cair dengan pelarut n-heksana dan menghasilkan ekstrak n-heksana 4,6 gram. Profil KLT-nya dapat dilihat pada tabel.

Hasil identifikasi ekstrak metanol secara kromatografi lapis tipis dengan menggunakan cairan pengelusi $n$-heksan : etil asetat $(8: 2)$, menunjukkan 4 bercak pada sinar UV $254 \mathrm{~nm}$,dan 5 bercak pada sinar UV $366 \mathrm{~nm}$, dan 5 noda pada penampak bercak uap iod Dan ekstrak nheksana secara kromatografi lapis tipis menggunakan cairan pengelusi $n$ heksana : etil asetat (8: 2) menunjukkan 4 bercak pada sinar UV $254 \mathrm{~nm}$, dan 5 bercak pada UV 366 $\mathrm{nm}$, dan 5 bercak pada penampak bercak $\mathrm{H} 2 \mathrm{SO} 4$ Profil KLT-nya dapat dilihat pada gambar 1-2 dan tabel 2-3. 
Isolasi komponen kimia ekstrak n-heksan daun pala (Myristica fragrans) secara kromatografi kolom konvensional menggunakan adsorben silika gel G. 60 dan cairan pengelusi nheksan : etil asetat (8) 2) sebanyak $300 \mathrm{ml}$, menghasilkan 37 vial, masingmasing vial tersebut diprofil KLT. Profil KLT dari ke 37 vial tersebut dapat dilihat pada gambar 3 dan tabel 4 .

Dari hasil profil KLT tersebut dikelompokkan fraksi berdasarkan nilai Rf-nya dan diperoleh 14 fraksi yaitu fraksi A, B, C, D, E, F, G, H, I, J, K, L, $M$, dan N. Selanjutnya diprofil KLT. Profil KLT dari ke 14 fraksi tersebut dapat dilihat pada gambar 4 dan tabel 5.

Selanjutnya fraksi $D$ dari kromatografi kolom konvensional ini diisolasi lagi secara kromatografi lapis tipis preparatif dimana diperoleh 3 pita. Selanjutnya diprofil KLT lalu disemprot dengan pereaksi spesifik flavonoid. Profil KLT-nya dapat dilihat pada gambar 5 dan tabel 6 .

Isolat pita I diuji kemurniaanya secara kromatografi lapis tipis dua dimensi, untuk elusi arah pertama menggunakan eluen $\mathrm{n}$-heksan : etil asetat $(8: 2)$ dan untuk arah kedua menggunakan eluen $n$-heksan : etil asetat $(8: 2)$. Selanjutnya disemprot dengan. Profil KLT-nya dapat dilihat pada gambar 6 dan tabel 7. Isolat D.1 yang diperoleh diuji kemurniannya lagi secara kromatografi lapis tipis multi eluen dengan variasi eluen yaitu pelat I menggunakan eluen $\mathrm{n}$-heksan : etil asetat $(8: 2)$, pelat II menggunakan eluen kloroform : metanol (15:6), dam pelat III menggunakan eluen klorofrom : n-heksan (1:1). Profil KLT-nya dapat dilihat pada gambar 7 dan table 8 .

Identifikasi dengan reaksi kmia yaitu dengan reagen $\mathrm{AlCl} 3$ memperlihatkan bercak kuning, pada uap iod memperlihatkan bercak berpendar, pada reagen vanillin- $\mathrm{HCl}$ memperlihatkan noda yang tidak tampak. Profil KLT-nya dapat dilihat pada gambar 8 dan tabel 9 .

Identifikasi secara spektroskopi ultra violet-visible menunjukkan serapan maksimum pada $273 \mathrm{~nm}$ sedangkan spektroskopi infra merah menunjukkan serapan pada panjang gelombang $3927.78 \mathrm{~cm}^{-1}, 3828.59 \mathrm{~cm}^{-}$ ${ }^{1}, 3743.30 \mathrm{~cm}^{-1}, 3387.93 \mathrm{~cm}^{-1}, 2925.93$ $\mathrm{cm}^{-1}, 2859.02 \mathrm{~cm}^{-1}, 2364.17 \mathrm{~cm}^{-1}$, $1642.54 \mathrm{~cm}^{-1}, 1565.88 \mathrm{~cm}^{-1}, 1516.65$ $\mathrm{cm}^{-1}, 1458.92 \mathrm{~cm}^{-1}, 1386.02 \mathrm{~cm}^{-1}$, $1114.33 \mathrm{~cm}^{-1}, 698.24 \mathrm{~cm}^{-1}$.

\section{KESIMPULAN}

Dari hasil penelitian yang telah dilakukan maka dapat disimpulkan bahwa isolat D.1 termasuk golongan 
flavonoid dengan panjang gelombang maksimum $273 \mathrm{~nm}$ dan

interpretasi spektrum infra merah menunjukkan gugus fungsi $(\mathrm{OH})$, alkil $(\mathrm{C}-\mathrm{H})$, gugus alken $(\mathrm{C}=\mathrm{C})$, gugus benzen serta didukung dari hasil penampak bercak flavonoid.

\section{DAFTAR PUSTAKA}

Arrijani., 2005. Biologi dan Konservasi Marga Myristica di Indonesia. Biodiversitas Vol.6 . ISSN 1412-033X. FMIPA Universitas Negri Manado Tondano 95187. e-mail;arjan_abdullah@yahoo.co.u $\mathrm{k}$

Chairul \& Sri Budi Sulianti., 2000 Perbandingan Komposisi
Kimia Penyususn Minyak Atsiri Pala Wegio (Myristica fatua I.) Dan Pala (Myristica fragrans L.) Degan FCMS. Kebun Raya Bogor. Laboratorium Fitokimia, Puslitbang Biologi LIPI. Bogor.

Hayne, K.,1987, Tumbuhan Berguna Indonesia II, Badan litbang Departemen Kehutanan, Jakarta

Miksusanti., Betty sri laksmi,J.,Rizal syarief, Bambang pontjo, Gatot tri mulyadi., 2009.,Antibacterial Activity Of Temu Kunci Tuber (Kaempheria pandurata) Essential Oil Against Bacillus cereus, Med J Indones, vol 18 No $1: 11$ 